TẠP CHÍ KHOA HỌC ĐẠI HỌC TÂN TRÀO

ISSN: 2354 - 1431

http://tckh.daihoctantrao.edu.vn/

\title{
Khảo sát và đánh giá chương trình đào tạo giáo viên mầm non của Trường Đại học Tân Trào giai đoạn 2006 - 2016
}

\author{
$H \grave{a} M \tilde{y} H a n h^{a^{*}}$ \\ ${ }^{a}$ Trưòng Đại học Tân Trào \\ EEmail:hamyhanhedu@gmail.com

\section{Thông tin bài viết}

Ngày nhận bài:

10/02/2018

Ngày duyệt đăng:

$12 / 6 / 2018$

Tù khoá:

Khảo sát, đánh giá, truò̀ng Đại học Tân Trào, chuoong trình đào tạo, giáo viên mầm non.

\section{Tóm tắt}

Khảo sát và đánh giá chương trình đào tạo là việc làm thường xuyên, là khâu quan trọng cung cấp những căn cứ thực tiễn có giá trị cho quá trình phát triển chương trình đào tạo. Một nghiên cứu trường hợp được thực hiện tại Trường Đại học Tân Trào và một số cơ sở giáo dục mầm non trên địa bàn tỉnh Tuyên Quang. Kết quả bước đầu cho thấy về cơ bản chương trình đào tạo giáo viên mầm non của Trường Đại học Tân Trào đã đáp ứng yêu cầu. Tuy nhiên, đối chiếu với những năng lực, phẩm chất của người giáo viên thế kỷ XXI thì cần phải tiếp tục điều chỉnh và phát triển.

\section{1. Đặt vấn đề}

Theo Thông tư số 12/2017/BGDĐT, ngày 19/5/2017 của Bộ GDĐT chương trình đào tạo ở một trình độ cụ thể bao gồm mục tiêu chung, mục tiêu cụ thể và chuẩn đầu ra đối với ngành học và mỗi học phần nội dung đào tạo, phương pháp đánh giá và thời lượng đối với ngành học, mỗi học phần. [1]

Việc tìm hiểu, đánh giá đúng thực trạng chương trình đào tạo giáo viên Mầm non là một công việc không thể thiếu nhằm tìm ra những thuận lợi, khó khăn, rào cản và nguyên nhân của chương trình đào tạo hiện hành từ đó có điều chỉnh kịp thời đáp ứng yêu cầu của thực tiễn.

Bài viết đi sâu phân tích khảo sát đánh giá chương trình đào tạo giáo viên mầm non Trường Đại học Tân Trào giai đoạn 2006 - 2016.

2. Khảo sát đánh giá chương trình đào tạo giáo viên mầm non Trường Đại học Tân Trào giai đoạn 2006 - 2016

\subsection{Mục đích khảo sát}

Việc đánh giá thực trạng chương trình đào tạo giáo viên mầm non giai đoạn 2006 - 2016 trên địa bàn tỉnh Tuyên Quang nhằm những mục tiêu cụ thể sau:

- Thu thập tình hình khách quan, số liệu thực tế về những vấn đề mà bài viết quan tâm.

- Khái quát hóa, phân tích và đánh giá tình hình thực trạng chương trình đào tạo giáo viên mầm non giai đoạn 2006 - 2016 trên địa bàn tỉnh Tuyên Quang.

- Từ đó rút ra những thuận lợi, khó khăn, rào cản và nguyên nhân của chương trình đào tạo giáo viên mầm non giai đoạn 2006 - 2016 trên địa bàn tỉnh Tuyên Quang.

\section{2. Đối tự̛ng khảo sát}

Chúng tôi tiến hành khảo sát 283 giảng viên $(\mathrm{GV})$, sinh viên ( $\mathrm{SV})$, cán bộ quản lý (CBQL), Cựu SV đang công tác tại trường Đại học Tân Trào; các trường Mầm non trên địa bàn tỉnh Tuyên Quang và khu vực Tây Bắc. Cụ thể được thể hiện ở bảng 1 : 
Bảng 1: Đối tượng khảo sát

\begin{tabular}{|c|l|c|}
\hline STT & \multicolumn{1}{|c|}{ Đối tượng khảo sát } & Mầm non \\
\hline 1 & CBQL, GV (ĐHTT) & 50 \\
\hline 2 & Sinh viên năm thứ 3 & 33 \\
\hline 3 & CBQL, GV (các trường phổ thông) & 100 \\
\hline 4 & Cựu sinh viên & $\mathbf{2 8 3}$ \\
\hline \multicolumn{2}{|c|}{ Tổng } & 33 \\
\hline
\end{tabular}

\subsection{Phương pháp khảo sát}

- Khảo sát bằng phiếu hỏi: chúng tôi sử dụng phương pháp này để điều tra $\mathrm{GV}, \mathrm{SV}, \mathrm{CBQL}, \mathrm{Cựu} \mathrm{SV}$ đang công tác tại trường Đại học Tân Trào; các trường Mầm non trên địa bàn tỉnh Tuyên Quang.

- Phuơng pháp lấy ý kiến chuyên gia: về bộ công cụ trước khi tiến hành điều tra.

- Phuoong pháp quan sát su pham: quan sát các hoạt động giáo dục, dạy học, hoạt động thực tế, hoạt động Đoàn, Đội và Hội SV... nhằm phát triển phát triển chương trình đào tạo giáo viên các bậc học Mầm non tỉnh Tuyên Quang.
- Phuơng pháp phỏng vấn: Tiến hành phỏng vấn tra $\mathrm{GV}, \mathrm{SV}, \mathrm{CBQL}, \mathrm{Cựu} \mathrm{SV}$ để làm rõ những vấn đề mà bảng hỏi và quan sát chưa thu thập được.

\subsection{Kết quả khảo sát}

2.4.1. Đánh giá về chuoong trình đào tạo giáo viên mầm non của truò̀ng Đại học Tân Trào

Để đánh giá về chương trình đào tạo giáo viên mầm non của Trường Đại học Tân Trào chúng tôi tiến hành điều tra bằng phiếu hỏi vừa kết hợp với phỏng vấn và quan sát nhằm giúp cho quá trình điều tra thực tiễn đạt hiệu quả cao.

Kết quả khảo sát chúng tôi thu được ở biểu đồ số 1 :

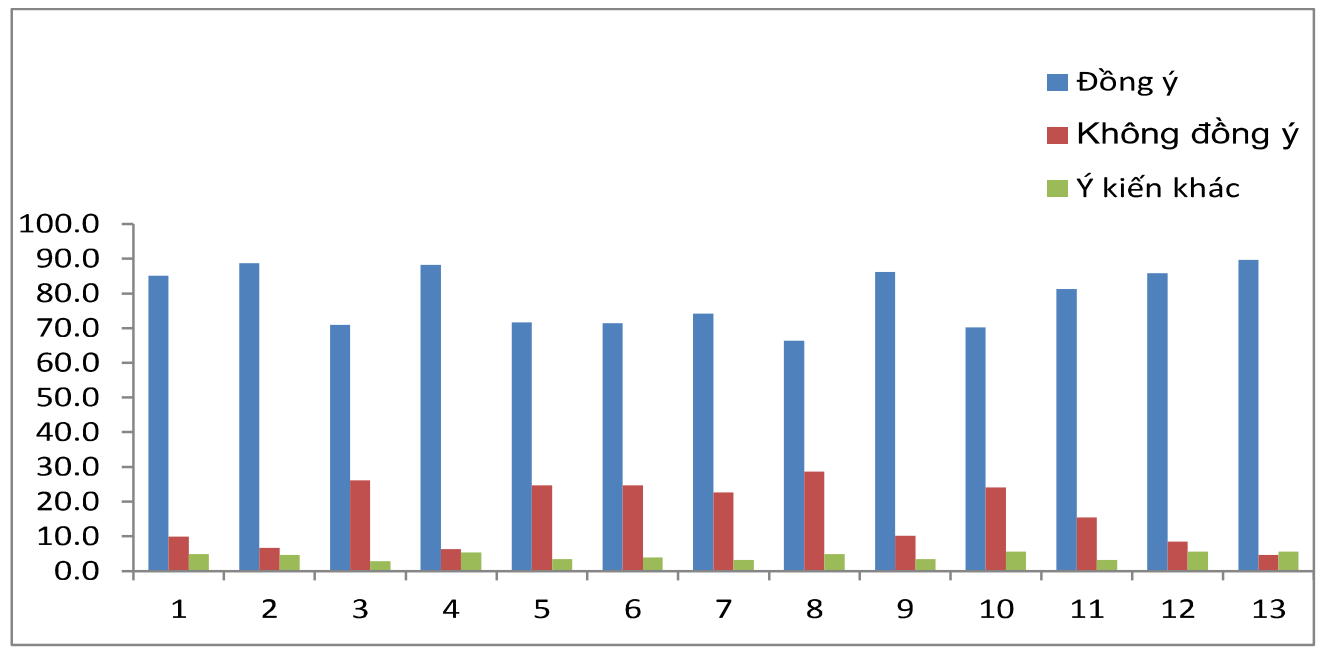

Biểu đồ 1: Đánh giá về chương trình đào tạo giáo viên mầm non của trường ĐHTT

Tiêu chí :

1. Chương trình đào tạo có sự linh hoạt, mềm dẻo, hợp lí

2. Chương trình đào tạo có mục tiêu và chuẩn đầu ra rõ rằng

3. Nội dung chương trình đảm bảo cập nhật, đổi mới

4. Nội dung chương trình đào tạo phù hợp với mục tiêu và chuẩn đầu ra của ngành học
5. Cấu trúc chương trình cân đối giữa khối kiến thức đại cương và kiến thức ngành

6. Tỉ lệ phân bố giữa số tiết lí thuyết và thực hành hợp lí

7. Số lượng các môn tự chọn đáp ứng nhu cầu của người học

8. Chương trình chú trọng đào tạo kĩ năng, năng lực nghề nghiệp cho sinh viên 
9. Các môn học trong chương trình được tổ chức, sắp xếp có hệ thống, logic

10. Chương trình đáp ứng yêu cầu công việc hiện nay của Anh/Chị

11. Chương trình đảm bảo liên thông với các chương trình khác

12. Kiểm tra, đánh giá kết quả học tập được thực hiện công bằng

13. Kiểm tra đánh giá dựa vào mục tiêu đào tạo.
14. Nhìn vào biểu đồ 1 cho thấy phần lớn các đối tượng điều tra đều đồng ý với 12 tiêu chí chương trình đào tạo giáo viên mầm non của Trường Đại học Tân Trào. Trong đó tiêu chí được đánh giá cao nhất $2,4,9$, 12,13 trên $85 \%$. Tuy nhiên, bên cạnh đó vẫn có một bộ phận không nhỏ đánh giá chương trình còn thiếu trang bị kỹ năng thể hiện việc không đồng ý với tiêu chí 8 chiếm $28,6 \%$.

2.4.2. Đánh giá về muc tiêu của chuoong trình đào tạo giáo viên Mầm non:

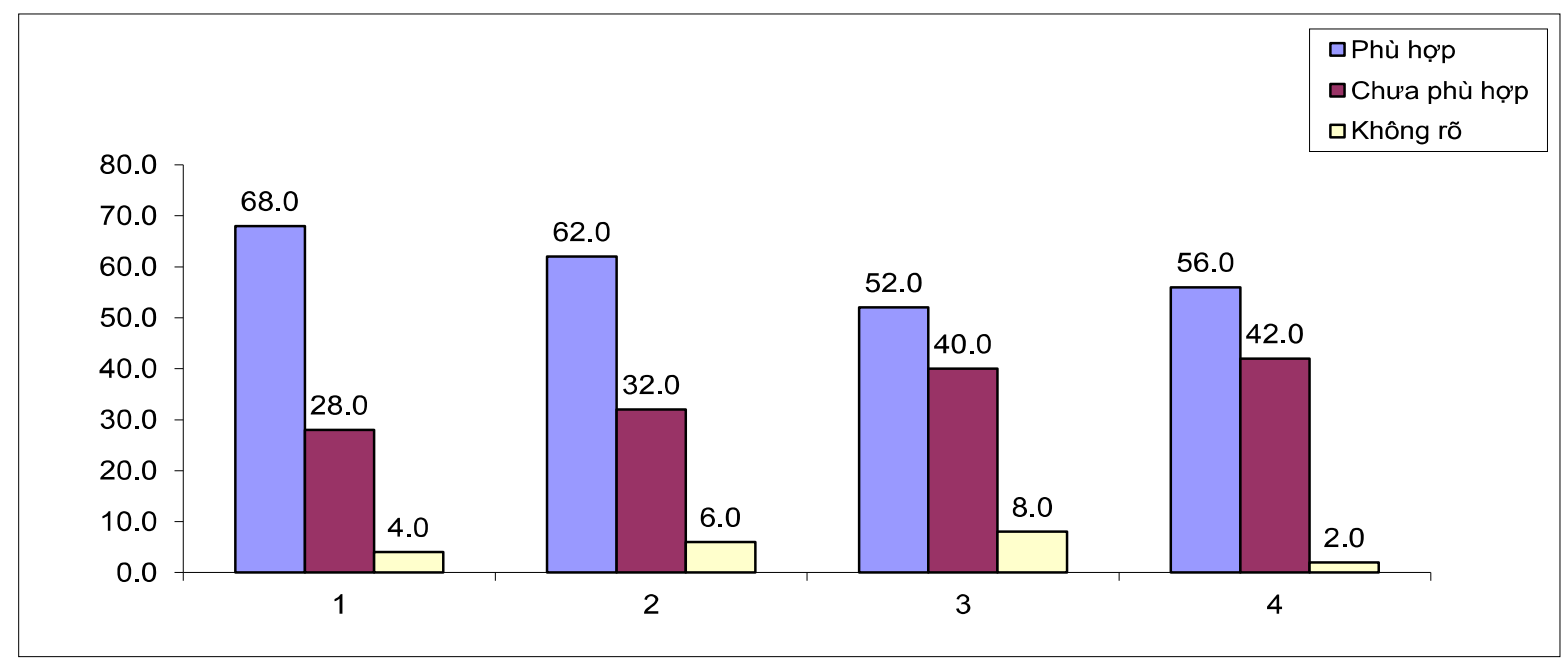

Biểu đồ 2: Đánh giá của CBQL, GV trường ĐHTT về mục tiêu của chương trình đào tạo giáo viên mầm non

Để tìm hiểu về mục tiêu của chương trình đào tạo giáo viên mầm non chúng tôi đã tiến hành khảo sát 50 CBQL, GV trường Đại học Tân Trào (ĐHTT) với 4 tiêu chí và tương ứng với 3 mức độ ( Phù hợp, chưa phù hợp và không rõ)

1. Mục tiêu của chương trình đào tạo được xác định rõ ràng, phù hợp với sứ mạng và tầm nhìn của cơ sở giáo dục đại học

2. Mục tiêu của chương trình đào tạo gắn với nhu cầu người học;

3. Mục tiêu của chương trình đào tạo gắn với nhu cầu nguồn nhân lực;

4. Mục tiêu của chương trình đào tạo được xác định theo đúng mục tiêu giáo dục đại học.

Nhìn vào biểu đồ số 2 cho thấy phần lớn CBQL, GV cho rằng mục tiêu của chương trình đào tạo mầm non được xác định rõ ràng, phù hợp với sứ mạng và tầm nhìn của cơ sở giáo dục đại học; Mục tiêu của chương trình đào tạo được xác định theo đúng mục tiêu giáo dục đại học (chiếm 68\%). Tuy nhiên, vẫn có ý kiến cho rằng mục tiêu của chương trình chưa gắn đào tạo gắn với nhu cầu người học (chiếm $32 \%$ ); chưa gắn với nhu cầu nguồn nhân lực (chiếm 40\%).

Để tìm hiểu thực trạng trên chúng tối tiến hành phỏng vấn một số giáo viên trong nhà trường thông qua câu hỏi: Tại sao thầy (cô) cho rằng muc tiêu của chuong trình đào tạo mầm non chua gắn đào tạo với nhu cầu người hoc và nhu cầu nguồn nhân lục?

Kết quả phỏng vấn thu được là: 18/20 CBQL, GV người được phỏng vấn các đều cho rằng do yêu cầu của quá trình đổi mới, sự phát triển nhanh chóng của khoa học kĩ thuật nên mục tiêu giáo dục đã có nhiều thay đổi do vậy mục tiêu của chương trình đào tạo mầm non hiện nay chưa gắn đào tạo gắn với nhu cầu người học và nhu cầu nguồn nhân lực. Điều này thể hiện giáo viên còn yếu và còn thiếu một số năng lực dạy học, năng lực giáo dục và đặc biệt là năng lực tin học, ngoại ngữ; năng lực hoạt động xã hội.

Thông qua quá trình quan sát chúng tôi cũng nhận thấy các em còn yếu và còn thiếu các năng lực dạy học, năng lực giáo dục và đặc biệt là năng lực tin học, 
ngoại ngữ; năng lực hoạt động xã hội. Nguyên nhân của tình trạng này là do nhiều nguyên nhân chủ quan và khách quan: nguyên nhân chủ quan là do các sinh viên chưa hực sự tích cực chủ động, còn ngại hoạt động thiếu chủ động, sáng tạo trong quá trình học tập. Nguyên nhân khách quan là do đội ngũ về giảng viên tin học, ngoại ngữ chưa đáp ứng được yêu cầu; cơ sở vật chất của nhà trường còn chưa phù hợp với yêu cầu đổi mới; Thiếu môi trường trải nghiệm; thiếu sự gắn kết giữa cơ sở đào tạo và các trường phổ thông.

2.4.3. Đánh giá của SV trừng ĐHTTvề mục tiêu, cấu trúc, nội dung các môn học trong chuơng trình đào tạo giáo viên mầm non

Để tìm hiểu đánh giá Đánh giá của $\mathrm{SV}$ trường ĐHTT về mục tiêu, cấu trúc, nội dung các môn học trong chương trình đào tạo giáo viên mầm non chúng tôi đã tiến hành khảo sát $100 \mathrm{SV}$ trường ĐHTT với 6 tiêu chí và tương ứng với 3 mức độ ( Đồng ý, Không đồng ý và Ý kiến khác).

1. Chương trình đào tạo có mục tiêu và chuẩn đầu ra rõ rang

2. Chương trình đào tạo phù hợp với mục tiêu và chuẩn đầu ra của ngành học

3. Cấu trúc chương trình cân đối giữa khối kiến thức giáo dục đại cương và kiến thức ngành

4. Tỉ lệ phân bố giữa số tiết lí thuyết và thực hành hợp lí

5. Số lượng các môn tự chọn đáp ứng nhu cầu của người học

6. Chương trình chú trọng đào tạo kĩ năng, năng lực nghề nghiệp của sinh viên

Kết quả được thể hiện ở biểu đồ số 3 .

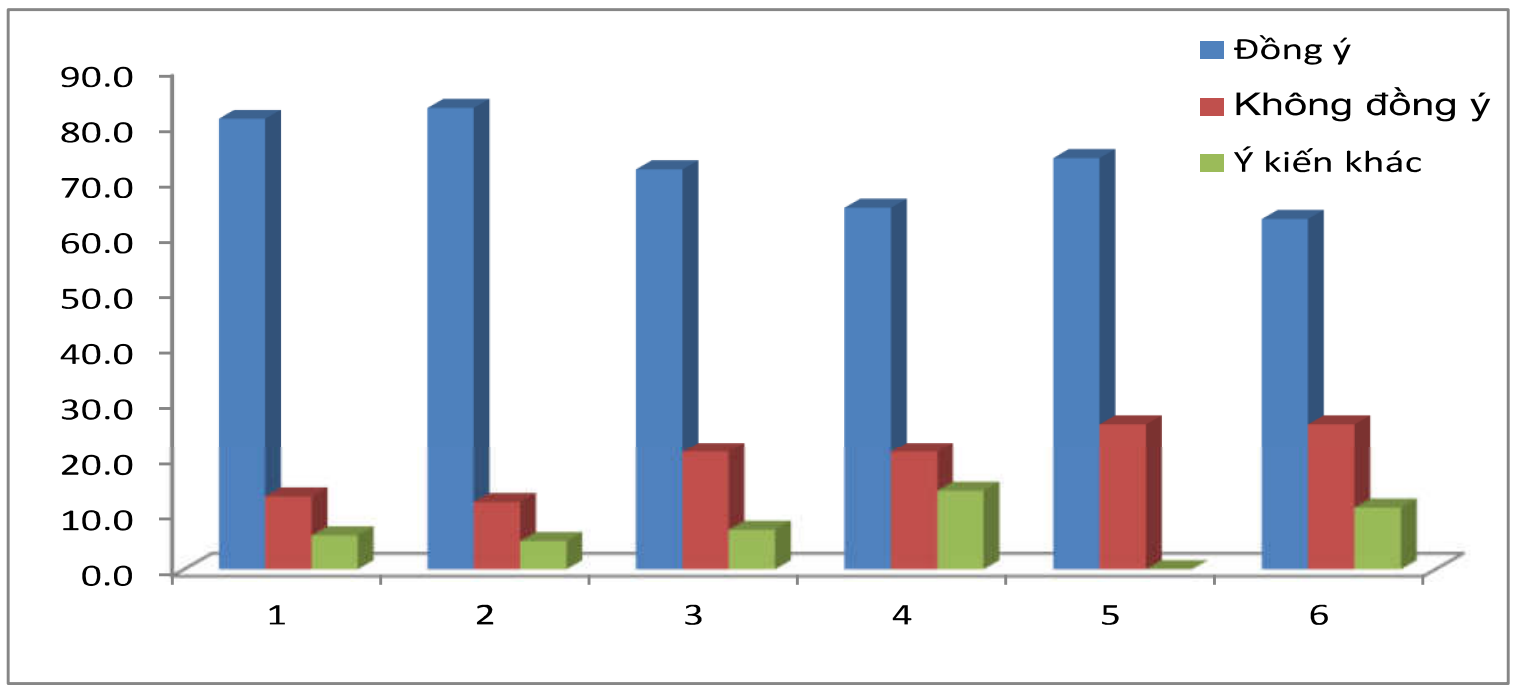

Biểu đồ 3: Đánh giá của SV trường ĐHTT về mục tiêu, cấu trúc, nội dung các môn học trong chương trình đào tạo giáo viên mầm non

Từ biểu đồ số 3 cho thấy phần lớn SV đều cho rằng: Chương trình đào tạo có mục tiêu và chuẩn đầu ra rõ ràng (chiếm $81,0 \%$ ); Chương trình đào tạo phù hợp với mục tiêu và chuẩn đầu ra của ngành học (chiếm 83,0\%); Cấu trúc chương trình cân đối giữa khối kiến thức giáo dục đại cương và kiến thức ngành (chiếm 72\%); Số lượng các môn tự chọn đáp ứng nhu cầu của người học (chiếm 74\%). Tuy nhiên, vẫn còn một bộ phận không nhỏ SV không đồng ý với quan điểm trên đặc biệt là $21 \%$ sinh không đồng ý với tiêu chí 4 (Tỉ lệ phân bố giữa số tiết lí thuyết và thực hành hợp lí) và $26 \% \mathrm{SV}$ được hỏi không đồng ý với tiêu chí 6 (Chương trình chú trọng đào tạo kĩ năng, năng lực nghề nghiệp của sinh viên). Để làm rõ vấn đề trên chúng tôi tiến hành phỏng vấn một số sinh viên thông qua câu hỏi: "Tại sao em không đồng ý với tiêu chí 4 (Tỉ lệ phân bố giũa số tiết lí thuyết và thực hành hợp li) và tiêu chí 6 (Chuoong trình chú trọng đào tạo kĩ năng, năng lục nghề nghiệp của sinh viên)?

Kết quả phỏng vấn thu được là hầu hết $\mathrm{SV}$ được hỏi đều cho rằng mặc dù chương trình đào tạo có mục tiêu và chuẩn đầu ra rõ ràng xong nội dung chương trình vẫn có sự mất cân đối giữa lý thuyết và thực hành, năm học 2015 - 2016 đã có giảm nội dung lý thuyết xong các học phần thực hành chưa thực sự phát huy được hiệu quả. Nguyên nhân là do sinh viên còn thụ động, chưa tích cực; Cơ sở vật chất chưa đáp ứng cho giờ thực hành; những giờ học thực tế còn it; 
chương trình còn chưa chú trọng đào tạo kĩ năng, năng lực nghề nghiệp của sinh viên; Sự phối hợp giữa trường đại học và phổ thông chưa thường xuyên; một bộ phận giáo viên còn ngại đổi mới...

Qua quan sát trong các giờ học, các hoạt động chúng tôi cũng nhận thấy nội dung kiến thức trong chương trình chủ yếu được $\mathrm{GV}$ trang bị cho $\mathrm{SV}$ vẫn là kiến thức lý thuyết trong tài liệu, giáo trình, GV chưa quan tâm nhiều đến những kiến thức có tính chất thực hành nghề nghiệp. Điều này còn thể hiện thông qua quá trình thực tập sư phạm một số $\mathrm{SV}$ còn tỏ ra lúng túng khi tổ chức các hoạt động cho học sinh và khi tiến hành thực tập nghề nghiệp.

Như vậy, mặc dù chương trình đào tạo có mục tiêu và chuẩn đầu ra rõ ràng, phù hợp xong nội dung chương trình vẫn có sự mất cân đối giữa lý thuyết và thực hành và Chương trình cần quan tâm hơn nữa việc đào tạo kĩ năng, năng lực nghề nghiệp của sinh viên.

2.4.4. Đánh giá của $C B Q L, G V$ các truòng mầm non về nhũng thuận lợi và khó khăn co bản trong quá trình quá trình giải dạy hiện nay ở truò̀ng mầm non

Để tìm hiểu đánh giá của $\mathrm{CBQL}, \mathrm{GV}$ về những thuận lợi và khó khăn cơ bản trong quá trình giảng dạy hiện nay ở trường chúng tôi đã tiến hành khảo sát 33 CBQL, GV ở các trường mầm non trên địa bàn tỉnh Tuyên Quang thông qua câu hỏi: Thầy/Cô cho biết nhũng thuận lợi và khó khăn co bản trong quá trình giảng dạy hiện nay ở trưòng?

Kết quả khảo sát được thể hiện ở bảng sau:

\section{Bảng Đánh giá của $\mathrm{CBQL}, \mathrm{GV}$ về những thuận lợi và khó khăn cơ bản trong quá trình giảng dạy hiện nay ở trường mầm non}

\begin{tabular}{|c|c|c|c|}
\hline \multirow{2}{*}{ TT } & \multirow{2}{*}{ Nội dung } & \multicolumn{2}{|c|}{ Lựa chọn } \\
\hline & & SL & TL(\%) \\
\hline 1 & Những thuận lọii & & \\
\hline a & Giáo viên được đào tạo cơ bản, đạt chuẩn & 33 & 100 \\
\hline $\mathrm{b}$ & Được đi tập huấn thường xuyên & 33 & 100 \\
\hline 2 & Những khó khăn & & \\
\hline $\mathrm{a}$ & Vận dụng linh hoạt các phương pháp giảng dạy & 33 & 100 \\
\hline $\mathrm{b}$ & Khả năng tiếp thu và tư duy của $G V$ còn hạn chế & 33 & 100 \\
\hline $\mathrm{c}$ & Phương pháp đánh giá mới & 33 & 100 \\
\hline d & Kiến thức cơ bản của một số giáo viên còn yếu & 33 & 100 \\
\hline đ & $\begin{array}{l}\text { Nội dung chương trình sách giáo khoa mới và phân phối chương } \\
\text { trình chưa thống nhất }\end{array}$ & 33 & 100 \\
\hline e & Thiết bị dạy học chưa đáp ứng được so với yêu cầu dạy và học & 33 & 100 \\
\hline $\mathrm{g}$ & Thông tin khoa học ít, đặc biệt là khoa học giáo dục & 33 & 100 \\
\hline $\mathrm{h}$ & Khả năng ứng dụng công nghệ thông tin trong giảng dạy & 33 & 100 \\
\hline
\end{tabular}

Từ bảng trên cho thấy $100 \% \mathrm{CBQL}, \mathrm{GV}$ đều cho rằng trong quá trình giảng dạy hiện nay ở trường có những thuận lợi: Giáo viên được đào tạo cơ bản, đạt chuẩn; Được đi tập huấn thường xuyên. $100 \% \mathrm{CBQL}$, GV đều cho rằng trong quá trình giảng dạy hiện nay ở trường có họ gặp phải những khó khăn: Vận dụng linh hoạt các phương pháp giảng dạy; Khả năng tiếp thu và tư duy của GV còn hạn chế; Phương pháp đánh giá mới; Kiến thức cơ bản của một số giáo viên còn yếu; Nội dung chương trình sách giáo khoa mới và phân phối chương trình chưa thống nhất; Thiết bị dạy học chưa đáp ứng được so với yêu cầu dạy và học; Thông tin khoa học ít, đặc biệt là khoa học giáo dục; Khả năng ứng dụng công nghệ thông tin trong giảng dạy. Tuy nhiên, mức độ khó 
khăn của từng tiêu chí là khác nhau trong đó khó khăn nhiều nhất mà hầu hết giáo viên đều gặp phải là vận dụng linh hoạt các phương pháp giảng dạy; Nội dung chương trình sách giáo khoa mới và phân phối chương trình chưa thống nhất; Thiết bị dạy học chưa đáp ứng được so với yêu cầu dạy và học và Khả năng ứng dụng công nghệ thông tin trong giảng dạy.

Để làm rõ hơn thực trạng trên chúng tôi tiến hành phỏng vấn 5 giáo viên và $3 \mathrm{CBQLGD}$ trường mầm non Lưỡng Vượng, Hoa Phượng và Trường mầm non Sông Lô thông qua câu hỏi: Thầy/cô có thể giải thích rõ về nhũng thuận lợi và khó khăn trên?

Kết quả phỏng vẫn cho thấy $5 / 5 \mathrm{GV}, \mathrm{CBQL}$ được hỏi đều cho rằng: Đội ngũ $\mathrm{GV}$ các trường hiện nay phần lớn đều có trình độ từ cao đẳng trở lên số $\mathrm{GV}$ trình độ trung cấp còn rất ít thường là những $\mathrm{GV}$ sắp về hưu. Hàng năm, các $G V$ đều được tham gia các lớp tập huấn, bồi dưỡng thường xuyên về đổi mới mục tiêu, nội dung, hình thức tổ chức và đặc biệt là phương pháp dạy học. Từ tháng $6 / 2018$, rất nhiều $G V$ có nhu cầu tham gia học tại các lớp bồi dưỡng về chuẩn chức danh nghề nghiệp giáo viên mầm non hạng 3 và hạng 2. Đây là những thuận lợi trong quá trình giảng dạy vì khi GV, CBQL được tham gia học tập nâng cao trình độ thì họ có nhiều thuận lợi trong đổi mới mục tiêu, nội dung, phương pháp và tổ chức linh hoạt các hoạt động của trẻ. Tuy nhiên, $\mathrm{GV}, \mathrm{CBQL}$ tại các trường mầm non còn gặp rất nhiều khó khăn trong quá trình giảng dạy như: Thói quen ngại thay đổi do nhận thức còn hạn chế, việc tự học tập nâng cao trình độ và đổi mới phương pháp dạy học còn hạn chế do thiết bị dạy học chưa đáp ứng được so với yêu cầu dạy học và khả năng ứng dụng công nghệ thông tin trong giảng dạy chưa thật sự tốt điều này ảnh hưởng không nhỏ tới kết quả giảng dạy trong các trường mầm non.

\section{5. Đánh giá chung}

Qua nghiên cứu, tổng kết thực tiễn và các kết quả từ khảo sát thực trạng chương trình đào tạo giáo viên mầm non chúng tôi đi đến một số kết luận sau:

- Phần lớn các đối tượng điều tra đều đồng ý với 12 tiêu chí chương trình đào tạo ngành giáo viên mầm non của trường Đại học Tân Trào. Trong đó tiêu chí được đánh giá cao nhất $2,4,9,12,13$ trên $85 \%$. Tuy nhiên, bên cạnh đó vẫn có một bộ phận không nhỏ đánh giá chương trình còn thiếu trang bị kỹ năng thể hiện việc không đồng ý với tiêu chí 8 chiếm $28,6 \%$.
- Mục tiêu của chương trình đào tạo giáo viên mầm non được xác định rõ ràng, phù hợp với sứ mạng và tầm nhìn của cơ sở giáo dục đại học; Mục tiêu của chương trình đào tạo được xác định theo đúng mục tiêu giáo dục đại học (chiếm 68\%). Tuy nhiên, vẫn có ý kiến cho rằng mục tiêu của chương trình chưa gắn đào tạo gắn với nhu cầu người học (chiếm $32 \%$ ); chưa gắn với nhu cầu nguồn nhân lực (chiếm 40\%).

- Mặc dù chương trình đào tạo có mục tiêu và chuẩn đầu ra rõ ràng, phù hợp xong nội dung chương trình vẫn có sự mất cân đối giữa lý thuyết và thực hành và chương trình cần quan tâm hơn nữa việc đào tạo kĩ năng, năng lực nghề nghiệp của sinh viên.

- $100 \% \mathrm{CBQL}, \mathrm{GV}$ đều cho rằng trong quá trình giảng dạy hiện nay ở trường có những thuận lợi: Giáo viên được đào tạo cơ bản, đạt chuẩn; Được đi tập huấn thường xuyên. $100 \% \mathrm{CBQL}, \mathrm{GV}$ đều cho rằng trong quá trình giảng dạy hiện nay ở trường có họ gặp phải những khó khăn: Vận dụng linh hoạt các phương pháp giảng dạy; Khả năng tiếp thu và tư duy của $\mathrm{GV}$ còn hạn chế; Phương pháp đánh giá mới; Kiến thức cơ bản của một số giáo viên còn yếu; Nội dung chương trình sách giáo khoa mới và phân phối chương trình chưa thống nhất; Thiết bị dạy học chưa đáp ứng được so với yêu cầu dạy và học; Thông tin khoa học ít, đặc biệt là khoa học giáo dục; Khả năng ứng dụng công nghệ thông tin trong giảng dạy. Tuy nhiên, mức độ khó khăn của từng tiêu chí là khác nhau trong đó khó khăn nhiều nhất mà hầu hết giáo viên đều gặp phải là Vận dụng linh hoạt các phương pháp giảng dạy; Nội dung chương trình sách giáo khoa mới và phân phối chương trình chưa thống nhất; Thiết bị dạy học chưa đáp ứng được so với yêu cầu dạy và học và Khả năng ứng dụng công nghệ thông tin trong giảng dạy.

\section{Kết luận}

Khảo sát và đánh giá chương trình đào tạo là khâu quan trọng cung cấp những căn cứ thực tiễn có giá trị cho quá trình xây dựng và phát triển chương trình đào tạo.

Thông qua khảo sát 283 người (cán bộ quản lý: 33 người, giáo viên: 50 người, sinh viên: 100 người và cựu sinh viên: 100 người) cho thấy về cơ bản chường trình đào tạo giáo viên màm non của trường Đại học Tân Trào giai đoạn 2006 - 2016 đã đáp ứng được yêu cầu nghề nghiệp giáo viên trên địa bàn tỉnh. Tuy nhiên, trước yêu cầu đổi mới căn bản toàn diện thì chương trình đào tạo giáo viên mầm non cần có sự điều chỉnh, phát triển theo hướng phát triển năng lực 
người học đặc biệt là chú trong phát triển kĩ năng sử dụng ngoại ngữ và tin học, các kĩ năng mềm trong thực hành nghề nghiệp nhằm đáp ứng yêu cầu về chuẩn nghề nghiệp giáo viên mầm non hiện nay.

\section{TÀI LIÊU THAM KHẢO}

1. Bộ giáo dục và Đào tạo, Thông tu Số 12/2017/BGDĐT, ngày 19/5/2017 thông tu ban hành quy định và kiểm định chất luợng co sở giáo dục đại học;
2. Hà Mỹ Hạnh (2016), Phát triển năng lục hoạt động xã hội cho sinh viên các truờng đại học su phạm khu vưc miền núi phía Bắc trong đào tạo theo học chế tín chỉ, Nxb Đại học Thái Nguyên;

3. Kỷ yếu hội thảo khoa học quốc tế "Đánh giá học sinh tiểu học bằng phuoong pháp tiếp cận năng lưc Giải pháp phù hơp của các co sở đào tạo giáo viên tại Việt Nam và một số nuoóc ASEAN", tháng 5/2015 tại Trường Đại học Tân Trào.

\section{Survey and evaluation the preschool teachers training programs of Tan Trao University during the period of $2006-2016$}

Ha My Hanh

\section{Article info}

Recieved:

10/02/2018

Accepted:

12/6/2018

Keywords:

Surveying, Assessment, Curriculum, Training Programs, Primary Teachers.

\begin{abstract}
Surveying and evaluating training programs is a regular activity and isan important step that provides valuable practical bases for the development of the curriculum. In the framework of this article, we focus on three issues: Survey Object and Scope, Survey Results and Overall Assessment of the Status of preschool teachers Training Program of Tan Tao University during the period of $2006-2016$.
\end{abstract}

